\title{
HORMONES AND METABOLISM IN PREGNANCY
}

\author{
A. Klopper, B.Sc., M.D., F.R.C.O.G. \\ J. M. Stowers, M.D, F.R.C.P. (Lond. \& Ed.) \\ I. MacGillivray, M.D., F.R.C.O.G. \\ T. Helgason, Cand. Med. Reykjavik \\ A. C. Turnbull, M.D., F.R.C.O.G. \\ K. J. Dennis, M.B., Ch.B., F.R.C.S.(Ed.), \\ M.R.C.O.G.
}

A. B. M. Anderson, M.D., D.Obst.R.C.O.G.

Department of Obstetrics and Gynaecology and the Maternity Hospital, Aberdeen.

THE marked changes in hormone production in pregnancy are associated with changes in metabolism and function. Much of the work which has been done and is being continued in the Clinical Research Unit of this department is concerned with the changes in body composition in rormal and abnormal pregnancy and the puerperium and in the uterine activity in labour. The earlier endocrine work had been principally concerned with the modification of research methods of urinary hormone assay to make them suitable for large scale clinical use. The more recent and the projected endocrine studies are being correlated as far as possible with the metabolic changes occurring in pregnancy, labour and the puerperium. The following is an account of some of the hormone and metabolic studies being carried out.

\section{THE STEROID HORMONES IN PREGNANCY Arnold Klopper}

Evidence has been accumulating from many centres which suggests that in late pregnancy the pregnanediol in the mother's urine is of purely placental origin, resulting from the metabolic breakdown by the mother of progesterone produced in the placenta. On the other hand, oestriol is a combined foetal and placental product, possibly formed in part from precursors produced in the foetal adrenals. It might be expected therefore that, while urinary pregnanediol was purely a reflection of the function of the placenta, the level of oestriol in the mother's urine might give some indication of the state of affairs in the foetus. A series of investigations has therefore been started with a view to examining the change in oestriol and pregnanediol output in such conditions as preeclampsia (Klopper, 1961), abortion (Klopper and Macnaughton, 1965), rhesus incompatibility (Klopper and Stephenson, 1966) and retarded intra-uterine foetal growth (Klopper, 1966). These studies have confirmed the view that oestriol assay is a valuable means of assessing the foetal state in a variety of obstetric diseases and routine assays are now done on a considerable proportion of the patients ad- mitted to the antenatal ward.

It has become evident that the degree to which oestriol output is affected is very much dependent on the nature of the obstetric disease. In rhesus incompatibility, even in cases where the baby is born moribund, the oestriol excretion is generally within normal limits. Similarly in diabetic pregnancy there appears to be no correlation between the maternal oestriol excretion and the condition of the foetus. On the other hand in pre-eclampsia there is a close correlation between oestriol excretion and the progress of the disease so that by serial assays it is often possible to tell when the life of the foetus is in peril. In the more insidious conditions associated with retarded intra-uterine foetal growth oestriol assay proved to be of particular value as there was often a close relationship between the oestriol level and the weight of the foetus with a tendency for oestriol output to decline to very low levels before intra-uterine death took place.

These findings raise the interesting question of what processes in the foetus are responsible for oestriol production and why some diseases should affect them and others not. Uterine 
blood flow may be of some impontance but is unlikely to be the sole factor concerned. It is hoped that a careful categorisation of hormone cxcretion in a variety of conditions may give some clue as to the relative importance of such factors as foetal oxygenation, maternal posture and activity, foetal liver and adrenal function and the adtivity of the sulphatase and p-glucuronidase enzyme systems responsible for steroid conjugation. Some studies on these lines have been published (Klopper, 1964), and others are in progress.

One of the most important problems in the study of the endocrinology of pregnancy today is the elucidation of the function of the hormones. Much work is being done elsewhere on the role of oestrogens at the cellular and molecular level. A clinical research unit such as exists in Aberdeen is particularly suited to the investigation of the physiological role of the hormones in such pregnancy phenomena as the onset of labour. At present, studies are being done comparing the changes in urinary oestriol and pregnanediol output with alterations in myometrial contractility and in cervical histology. It may well be that in part the effect of oestrogens on the onset of labour is exercised by oestrogen-induced changes in the polymerization of cervical mucopolysaccharides. The relationship between oestrogen levels and ground substance generally has been little studied and we intend to devote increasing attention to this aspect.

Urinary steroid assays have proved to be of value in day-to-day clinical management of obstetric patients. They are less useful in fundamental physiological studies because many processes which might alter the urinary level are interposed between steroid production in the foetoplacental unit and its final excretion in the maternal urine. Urinary levels may not be a true reflection of the endocrine environment obtaining at the level of the foetus or the myometrium. It may well be that events such as the onselt of labour result from endocrine changes engendered by the foeto-placental unit rather than from the maternal organism. If this is the case it is essential to study these changes at the foeto-placental level. The biological fluids which, one way or another, are available for study are: maternal peripheral blood, maternal uterine venous and retroplacental blood, liquor amnii and cord vein or artery foetal blood. It may well be that much valuable information about the physiology of pregnancy can be gained by studying the concentration of the free and conjugated forms of various steroid hormones in these biological fluids. The steroids we propose to concentrate on are oestriol, pregnanediol, progesterone and dehydroepiandrosterone, the raw material from which the other steroids are made. Hitherto the methods for estimating the tiny amounts of steroids present in such biological fluids have been unsatisfactory. The advent of gas liquid chromatography has opened a new dimension in steroid estimation. It appears very likely that satisfactory methods for the estimation of oestriol and of pregnanediol in blood and liquor amnii will be evolved over the next iew months. The applications of such methods both to physiological and to clinical problems are legion.

A further aspect of the role of hormones in pregnancy is their metabolic effects. In this context studies on the role of the oestrogens on water balance have been published (Hytten and Klopper, 1963). This led to an interest in the relationship between renal function and hormone excretion in pregnancy (Klopper, 1964) and to an investigation, which is still continuing, cff the effect of progesterone on sodium excretion by blocking the action of aldosterone on the renal tubules.

The accumulation of fat which occurs in pregnancy is very probably due to progesterone (Galleti and Klopper 1964).

The metabolic changes of pregnancy appear to be rapidly reversed after delivery. A study of water and electrolyte balance during the puerperium may therefore be of especial interest and the fact that such a study is being done in the Department has been made the occasion of a coincidental analysis of hormone excretion during the puerperium.

\section{WATER AND ELECTROLYTE META BOLISM IN NORMAL AND ABNORMAL PREGNANCY \\ Ian MacGillivray}

Most of the hormonal changes occurring in pregnancy are concerned with the growth of the baby and the changes in the maternal organs to accommodate and provide for the developing foetus. Because of the inaccessibility it is difficult to measure with any accuracy the rate of growth of the baby but the response of the mother to the hormonal changes and metabolic processes can often reflect the condition of the foetus. Thus an assessment of such changes in the mother might be expected to help in reducing perinatal mortality and morbidity. 
Water forms about half of the weight of nonpregnant females and changes in the water content of the pregnant woman might be expected as there is normally an increase in plasma volume of about $1350 \mathrm{ml}$. (Hytten and Paintin, 1963); a volume of liquor amnii of about 1000 ml.; and water forms about $80 \%$ of baby weight. An excess of water as evidenced by clinical oedema is one of the signs of pre-eclamptic toxaemia and Hytten and Paintin (1963) have shown that women with a poor increase in plasma volume produce smaller babies; Hytten has suggested that deficient water retention is associated with retarded foetal growth.

Although the total body water can be measured with some precision by tracer techniques using, for example, deuterium oxide (Hytten, Taggart, Billewicz and Jason, 1962) the compartmental distribution cannot be measured with the same accuracy because the intracellular and extracellular fluids are in a constant state of flux and there is no known substance which entirely equilibrates with the extracellular fluid yet does not penetrate into the cells.

In normal pregnancy near term there is a retention of about 6-7 litres of water as measured by deuterium oxide (Hutchinson, Plentl and Taylor, 1954; Haley and Woodbury, 1956; McCartney, Pottinger and Harrod, 1959; MacGillivray, 1961a). The "extracellular" space was found to be about $55 \%$ of the total body water in 12 normal pregnant women (thiocyanate space, $53.9 \%$; bromide space, $56.2 \%$ sodium space $54 \%$ ) by MacGillivray (1961a). This is higher than in the non-pregnant female in whom the range is from $41 \%$ thiocynate space to $50.3 \%$ bromide space (Schloerb, Friis-Hansen, Edelman, Solomon and Moore, 1950; Edelman, Haley, Schloerb, Sheldon, Friis-Hansen, Stool and Moore, 1952; Gilder, Redo, Bar and Child, 1954; Ikkos, Ljunggren, Luft and Sjögren, 1955).

In pre-eclamptic toxaemia there is a retention of fluid greater than in normal pregnancy. The results for 12 normal primigravidae near term, 17 primigravidae with mild and 14 with severe

\section{TABLE 1}

Total Body Waiter In Normal Pregnancy and Pre-Eclamptic Toxaemia (P.E.T.)

Normal Pregnancy

Mild P.E.T. with oedema

$38.4 \mathrm{~L}$.

Mild P.E.T. without oedema

Severe P.E.T. with oedema

Severe P.E.T. without oedema

$43.5 \mathrm{~L}$.

$39.4 \mathrm{~L}$.

$43.2 \mathrm{~L}$.

$40.5 \mathrm{~L}$.

pre-eclampsia are shown in Table 1 (from MacGillivray, 1961b). In normal pregnancy there is an increase in the serum volume both absolute and as a proportion of the total fluid volume. In pre-eclampsia there is a reduction in the serum volume compared with normal pregnancy both in absolute amount as well as in terms of total water. (Table 2).

The "extracellular" space in pre-eclampsia is slightly greater than in normal pregnancy when measured as sodium space but the bromide space is about the same. The "extracellular" space as a percentage of total body water is less in pre-eclampsia than in normal pregnancy. (Table 3). The cause of the retention of fluid in normal pregnancy and in pre-eclampsia is still obscure. The various hormones which have been suggested are oestrogens, progesterone, adrenocortical hormones, growth hormone and antidiuretic hormone. One or several of these hormones may be involved in the retention of fluid in normal pregnancy and pre-eclampsia and they may act by causing a pnimary water retention or a primary sodium retention. The oedema which is common in pregnancy and pre-eclampsia may be caused or contributed to by some other factor such as the lowering of colloid osmotic pressure. It is widely accepted that nutritional oedema occurs when the total proteins fall below 5 per cent and the serum albumin below 2.5 per cent. The total proteins and serum albumin fall quite markedly in normal pregnancy (MacGillivray and Tovey, 1957; Paaby, 1960; de Alvarez, Afonso and Sherrard, 1961) and still further in pre-eclamptic toxaemia.

TABLE 2

Serum Volume in Normal Pregnancy and Pre-Eclamptic Toxaemia (P.E.T.)

$\begin{array}{lcccc} & \begin{array}{c}\text { No. of } \\ \text { Cases }\end{array} & \begin{array}{c}\text { Mean Serum } \\ \text { Volume L. }\end{array} & \begin{array}{c}\text { Serum Volume } \\ \%\end{array} \text { T.B. Water } & \begin{array}{c}\text { Range and } \\ \text { S.D. }\end{array} \\ \text { Normal Pregnancy } & 9 & 4.1 & 10.6 & (8.2-13.5) \\ \text { Mild P.E.T. } & 15 & 3.5 & 8.7 & 1.48 \\ \text { Severe P.E.T. } & 11 & 3.4 & 8.2 & (6.4-10.6) \\ \text { Non Pregnant* } & \text { *Schloerb et al. 1950; Gilder } \text { et al. } 1954 \text {; and Zak and Earle, } 1957 . & 1.13 \\ & & \end{array}$

Range and S.D. 1.48 1.13 $1-11.7)$ 1.55 


\section{TABLE 3}

Bromide and Sodium Spaces Rel.ated to Total Body Water in Normal Pregnancy and Pre-Eclamptic Toxaemia (P.E.T.)

\begin{tabular}{lrrrrr} 
& \multicolumn{2}{c}{ Br. Space } & & \multicolumn{2}{c}{ Na. Space } \\
& $\%$ & T.B.W. & & $\%$ T.B.W \\
Normal Pregnancy & 56.2 & $(7)$ & & 54.9 & $(12)$ \\
Mild P.E.T. & 49.4 & $(10)$ & 52.1 & $(17)$ \\
Severe P.E.T. & 48.5 & $(7)$ & & 52.0 & $(12)$
\end{tabular}

Number of cases in brackets

The part played by electrolyte changes in the causation of the oedema of pre-eclampsia remains controversial. Since Harding and van Wyck (1931), Strauss (1937) and Dieckmann (1950) showed that giving sodium chloride to women with pregnancy toxaemia could cause a marked aggravation of hypertension, oedema and even eclampsia it has become popular amongst clinicians to consider that sodium retention is the cause of the oedema of pre-eclampsia and that elimination of sodium will improve the condition. There is no convincing evidence that either of these beliefs is correct.

Studies of total exchangeable electrolytes have shown that in normal pregnancy there is an average increase of $773 \mathrm{mEq}$. of sodium (MacGillivray and Buchanan, 1958) which is similar to the amount calculated by Hytten and Leitch (1964) and the balance study of Hummel, Hunscher, Bates, Bonner and Macey (1937). The increase in exchangeable chloride was 480 $\mathrm{mEq}$. and of potassium $170 \mathrm{mEq}$. (MacGillivray, 1961a). The amount of sodium and chloride per litre of body water is about the same in normal pregnancy as in the non-pregnant female but in mild and severe pre-eclamptic toxaemia there is less sodium and chloride per litre total body water. (Table 4).

MoCartney, Pottinger and Harrod (1959), Plentl and Gray (1959) and Mahran (1961) believe that there is more sodium than water retained in pre-eclamptic toxaemia but Davey, O'Sullivan and Browne (1961) have confirmed that the amount of water retained is relatively greater than the amount of sodium.

It is difficult to reconcile these two opposing views and it is of obvious importance to do so if the underlying hormonal change is to be indentified. This is also of importance clinically in view of the potential dangers of giving sodium diuretics. Although they undoubtedly eliminate sodium they have little if any effect on the clinical course of the pre-eclamptic toxaemia (MacGillivray, Hytten, Taggart and Buchanan, 1962) and could cause salt deficiency.

As the range of values is wide (Table 4) it may be that there is a fluctuation in the salt: water ratio and in the hormonal blood levels. For example, blood oestrogens which couldळ have an effect on sodium retention have been shown (Roy, Harkness and Kerr, 1963) to beo either higher or lower in women with pre-eclamp tic toxaemia than in normal pregnancy. This is rather similar to the situations of water intoxication (Leaf, Bartter, Santos and Wrong, 1953) and hypernatraemic water depletion (Edelman, Leibman, O'Meara and Birkenfeld, 1958) in which total body sodium and plasma sodium move in an opposite direction to the volume of extracellular fluid. Bartter, Liddle, Duncan,

TABLE 4

Total Exchangeable Sodium and Chloride PER Litre Total Body Water in Non-Pregnant, Normal Pregnant, and Pre-Eclamptic Toxaemia (P.E.T.)

\begin{tabular}{|l|c|c|c|c|} 
& $\begin{array}{c}\text { Na e/L. } \\
\text { T.B.W. }\end{array}$ & $\begin{array}{c}\text { Range and } \\
\text { S.D. }\end{array}$ & $\begin{array}{c}\text { C1 e/L. } \\
\text { T.B.W. }\end{array}$ & $\begin{array}{c}\text { Range and } \\
\text { S.D. }\end{array}$ \\
\hline Normal Pregnancy & 78.1 & $(70.5-90.8)$ & 57.6 & $(46.1-68.3)$ \\
Mild P.E.T. & 72.8 & 5.74 & 7.82 \\
Severe P.E.T. & 72.7 & $(61.5-83.1)$ & 50.9 & $(40.3-59.0)$ \\
Non Pregnant & $77.6 *$ & 5.53 & 51.00 \\
\hline
\end{tabular}

*Edelman et al. (1952)

†Ikkos et al. (1955) and McMurrey et al. (1958) 
Barber and Delea (1956) have shown that urinary aldosterone is reduced in experimental water intoxication and increased in water deprivation associated with high serum sodium. The amount of circulating aldosterone is diminished in pre-eclamptic toxaemia (Louros, Miras and Frangiadakis, 1960; De Bruine, 1960) as is the amount of renin, which through its conversion product angiotensin, stimulates the secretion of aldosterone (Brown, Davies, Lever and Robertson, 1965).

Brown and his co-workers (1965) however, have shown that suppression of plasma renin in patients with primary aldosteronism appears to be the result of an increase in the body sodium and of the volume of extracellular fluid. This adds to the difficulties of interpreting the results of studies of patients with pre-eclamptic toxaemia. It will probably be necessary to do combined studies of blood hormonal values (e.g. oestrogens and aldosterone) and total water and electrolyte values in normal and abnormal pregnancies in order to determine whether there is a primary water or sodium retention in preeclamptic toxaemia.

\section{HORMONAL REGULATION OF UTERINE FUNCTION IN PREGNANCY AND LABOUR}

\section{A. C. Turnbull and A. B. M. Anderson}

The part played by hormones in the regulation of uterine function in pregnancy and labour is still uncertain.

Intra-amniotic injection of saline causes abortion or labour and it has been claimed (Bengtsson and Csapo, 1962) that the injection damages the placenta to such an extent that its production of hormones is greatly reduced. The "progesterone block" is thus removed from the myometrium, and labour begins.

Turnbull and Anderson (1965) showed that uterine activity began to increase 40-80 minutes after the hypertonic saline injection and the intensity of contractions increased steadily until abortion, reaching an average level of $95 \mathrm{~mm}$. of mencury, twice as high as that in full-term labour. Bengtsson and Csapo (1962) believe that such high pressures resulted from the complete withdrawal of the "progesterone block". Anderson, Turnbull and Murray (1966) have demonstrated, however, that relationship between myometrial tension and amniotic fluid pressure during a contraction depends on the size of the uterus; the smaller the uterus, the higher the pressure resulting from the same myometrial tension. They calculated that the myometrial tension required to produce $95 \mathrm{~mm}$. amniotic pressure with contractions at 20 weeks would produce contractions of "normal" intensity at full term-about 45 to $50 \mathrm{~mm}$. of mercury.

Furthermore, Klopper, Turnbull and Anderson (1966) have shown that after the intraamniotic injection of hypertonic saline, pregnanediol excretion is maintained at 85 per cent of the mean pre-injection level until after the placenta and foetus are aborted, indicating continuing progesterone production by the placenta. Oestriol excretion falls immediately after the injection, due to intra-uterine foetal death, although this is not essential to the success of the method. Usually, however, these abortions must occur despite a great excess of progesterone relative to oestrogen.

Christie, Anderson, Turnbull and Beck (1966) have shown that placental damage is limited to a thin subchorionic layer (amounting at most to 15 per cent of placental thickness) in which there is intervillous thrombosis and necrosis of villi. In the remaining 85 per cent or more of the placenta which was histologically normal, new immunofluorescent techniques indicated normal concentration of placental growth hormone and of steroids within the syncytiotrophoblast, in keeping with normal function.

About 40 to 80 minutes after the hypertonic saline injection a marked antiduresis develops (to a water load of $800 \mathrm{ml}$./hour). (Turnbull and Anderson, 1966; also unpublished data). The excess salt clearly begins to flow out into the maternal circulation for increases in serum sodium concentration of up to $160 \mathrm{~m}$.Eq./litre have been found, despite increases in serum volume of up to $1400 \mathrm{ml}$. Serum osmolality has also risen as high as $296 \mathrm{mOsmol} / \mathrm{Kg}$. These changes have varied in degree and duration but Turnbull and Anderson (1966) have drawn attention to the risks of these changes if the technique was to be used in patients with cardiac or renal disease.

Increased uterine activity following intraamniotic saline injection may be the result of direct effects of electrolytes on the myometrium rather than the result of any effect on placental steroid production.

Uterine contractility during pregnancy has been recorded by Turnbull and Anderson (unpublished) and differences in activity demonstrated in patients in whom labour was 
premature, (up to 37 weeks), pre-term, (38-40 weeks), and post-term, (41 + weeks). Urinary excretion and blood levels of placental steroids and their metabolites are being measured in the different groups, in conjunction with Dr. A. Klopper.

The changes in the connective tissue of the cervix during pregnancy have been studied by ordinary histological methods and by measurung nydroxyproline and hexosamine concentration in biopsies of cervix with a view to relating the "resistance" of the cervix to the progress of labour. The changes are part of a general effect of steroids on connective tissue in pregnancy which has also been studied in other tissues. The changes in the cervix appear to be very marked in younger women, (Turnbull, 1962) but less in those over 30 years of age.
Considerable variation in uterine sensitivity to oxytocin can be demonstrated both by clinical observation and experiment in cases in whom induction of labour is required in late pregnancy. Recognising this, Turnbull and Anderson have developed an oxytocin "titration" for clinical use, usually for failed amniotomy, with dosage increasing from $1 \mathrm{mU} . / \mathrm{min}$. to as high as $128 \mathrm{mU} . / \mathrm{min}$. of oxytocin depending on the activity of the uterus. Careful preliminary studies were made with constant in- of fusion of oxytocin. The results with this technique in almost 500 cases of induction are now being prepared for publication and indicate considerable improvement in the success rate over the previous regime for induction as well as reduction in the inoidence of intrauterine infection, Caesarean Section and foetal asphyxia.

\section{THE INTRAVENOUS GLUCOSE TOLERANCE TEST IN PREGNANCY}

\section{J. M. Stowers and T. Helgason.}

The oral glucose tolerance test in pregnancy is relatively unsatisfactory because nausea and vomiting may be precipitated and there is a tendency for delayed absorption causing the 2 -hour glucose value to be increased well above the fasting value, (Hagen, 1961) even in those in whom there is no reason to suspect diabetes. The correlation between oral and intravenous glucose tolerance tests is poor (Kaplan, 1961; Welsh, 1960) probably mainly because of the factor of delayed intestinal absorption of glucose. In pregnancy intravenous glucose tolerance has usually been described as being no less than in the non-pregnant state (Burt, 1954). In the work done in Aberdeen this conclusion has been accepted and the same standards of interpretation have been applied in the pregnant as in the non-pregnant. In calculating results the "Increment Index" (Duncan, 1956), based on increments of the blood sugar above the fasting level, has been used in preference to the absolute or $\mathbf{K}$ Index, which is derived from the absolute blood sugar values. The theoretical basis for the Increment Index seems to be superior to that of the absolute index (Medley, 1965), and the Increment Index, but not the absolute index, is independent of the amount of glucose injected. Heparin is used to inhibiit venous thrombosis and the test is done after the subject has remained quietly at rest for at least twenty minutes. The present series is the largest reported of the results of intravenous glucose testing in pregnancy and the puerpenium. 720 subjects were tested over a four-year period.

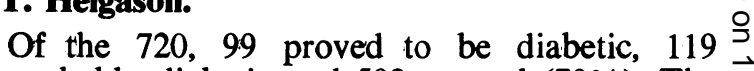
probably diabetic and 502 normal $(70 \%)$. The $\vec{c}$ reasons for the tests were various, but the commonest was the finding of glycosuria which $\vec{\theta}$ occurred in $70 \%$ of the whole series. Wheg glycosuria was the only indication for the test in 233 subjects $27.2 \%$ had abnormal glucose tolerance and in $10.6 \%$ the result was definitely diabetic. Those already known to be diabetic have been excluded from consideration.

The most significant indication for doing the intravenous glucose tolerance test was the previous birth of a baby weighing $10 \mathrm{lb}$. (4.5 Kg.) or more. This was the reason for the test in 156 of the 720 subjects. $35 \%$ of those proved to be diabetic had had such a heavy baby, whereas the figure was $19.2 \%$ for the probable diabetics and $19.7 \%$ of those shown to have nonmal i.v. glucose tolerance. Obesity, defined as at least 2 st. above the Kemsley (Kemsley, 1951-52) standard weight allowing for the stage of pregnancy, was found in $29.7 \%$ of the 99 diabetics, $27.5 \%$ of the 119 probable $\frac{7}{0}$ diabetics and in only $14.7 \%$ of the normals diagnosed during pregnancy or the puerperium. $N$ Multiparity, defined by seven or more preg- N nancies carried to at least 28 weeks occurred 0 in $5.1 \%$ of the diabetics, $4.2 \%$ of the probable $\mathrm{\omega}$ diabetics and in only $2.4 \%$ of the normals. Abortions occurred in $26.5 \%$ of the diabetics, $21.6 \%$ of the probable diabetics and $16.7 \% \stackrel{\Phi}{\oplus}$ of the normals. The significance of various co-existing indications for glucose testing has been analysed in Table 5. It is noteworthy that only $50 \%$ had a normal intravenous glucose 
TABLE 5

Significance of Various Combinations of Indications for I. V. Glucose Testing

$\begin{array}{lcccc} & \text { Total } & \begin{array}{c}\text { Diabetic } \\ \%\end{array} & \begin{array}{c}\text { Probable } \\ \text { Diabetic } \\ \%\end{array} & \text { Normal } \\ \begin{array}{l}\text { Glycosuria alone } \\ \begin{array}{c}\text { Glycosuria + baby of } 10 \mathrm{lb} . \\ \text { (4.5 Kg.) or more }\end{array}\end{array} & 233 & 10.6 & 16.6 & 72.8 \\ \begin{array}{c}\text { Glycosuria + obesity } \\ \text { (2 st. or 12.7 Kg. above }\end{array} & 51 & 21.5 & 17.8 & 61 \\ \begin{array}{c}\text { Kemsley Standard) } \\ \text { Big baby + obesity }\end{array} & 80 & 22.5 & 20 & 57.5 \\ + \text { /- glycosuria } & 44 & 31.8 & 18.2 & 50\end{array}$

TABDLE 6

IN PREGNANCY

Diabetics

Probable Diabetics

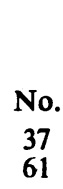

37
61

\begin{tabular}{ccr}
\multicolumn{3}{c}{ POST-PARTUM } \\
Diabetics & $\begin{array}{c}\text { Probable } \\
\text { Diabetics }\end{array}$ \\
9 & 6 & Normal \\
15 & 4 & $42(60 \%)$ \\
& 4 &
\end{tabular}

tolerance when the mother was obese and had had a $10 \mathrm{lb}$. (4.5 Kg.) baby.

The intravenous glucose tolerance test results did not correlate significantly with positive family history of diabetes mellitus, a history of stillbirths, neo-natal deaths or of foetal abnormality. Hydramnios is difficult to assess objectively and was seldom an indication for intravenous glucose testing. The diabetic group had a mean duration of pregnancy of 38 weeks, the probable diabetics of 39 weeks and the normals of 40.1 weeks. Allowing for the differences in the gestational period the mean baby weight was $40 \%$ or more above the normal mean (equivalent to $10 \mathrm{lb}$. or more at 40 weeks) in $13.1 \%$ of the diabetics, $10.6 \%$ of the probable diabetics and $3.7 \%$ of the normals. Sixty per cent of the diabetics diagnosed during pregnancy had a normal i.v. glucose tolerance in the puerperium. In the series of probable diabetics $69 \%$ became normal post-partum but $25 \%$ regressed to the diabetic state. The results of a comparison of postpartum intravenous tests with those performed during pregnancy are presented in Table 6 which indicates that intravenous glucose intolerance demonstrated for the first time in pregnancy frequently persists and may indeed progress post-partum.

\section{CHANGES IN THYROID FUNCTION AND IODINE METABOLISM DURING PREGNANCY}

A. C. Turnbull

It is generally agreed that abnormal function of the thyroid gland during pregnancy may predispose to complications such as abortion but before such dysfunction can be recognised the physiological changes in thyroid function during pregnancy have to be understood.

Visible and palpable enlargement of the thyroid gland occurred in $70 \%$ of 184 pregnant women in Aberdeen and in $37 \%$ of 116 nonpregnant controls of similar age and social status from the same area (Aboul-Khair, Crooks, Turnbull and Hytten, 1964). The distribution of goitre in pregnancy was not influenced by mater- nal age, parity and stage of gestation.

Serial studies using the short lived isotope ${ }^{132}$ I were made in 13 women at the 12 th, 16 th. $24 \mathrm{th}, 32 \mathrm{nd}$ and $36 \mathrm{th}$ weeks of pregnancy and in the 2nd, 6th and 12th weeks post-partum. (Aboul-Khair, Crooks, Turnbull and Hytten, 1964). Renal clearance of iodine increased early in pregnancy to a level twice that normally found and this was associated with a low plasma inorganic iodine (even allowing for dilution by the increased serum volume which was also narrowed). Thyroid clearance rate of iodine increased to about three times normal 
but absolute uptake of iodine remained within the euthyroid range. These changes were found before the 12th week, persisted until term and returned to normal levels by the 6th week post-partum.

Pregnancy therefore results in an iodine deficiency state, partly due to a high renal clearance of iodine, and the thyroid gland as a compensating mechanism, apparently, clears more plasma of its iodine to produce a normal amount of thyroid hormone and in doing so, increases in size.

The same technique has been used to study iodine metabolism in cases of abortion and habitual abortion, premature labour, "placental dysfunction", pre-eclampsia and "other hypertension" in pregnancy. (Aboul-Khair, Crooks, Turnbull and Turnbull, 1966). There is some evidence of reduced thyroid function in habitual abortion and in premature labour, while in pre-eclampsia the renal clearance of iodine is at normal non-pregnant levels while in "other hypertensives" it is almost normal for pregnancy. These differences could be explained by reduction in renal blood flow and GFR in pre-eclampsia. In some cases where small babies were born at term, thyroid function was diminished.

In cases where therapeutic termination of pregnancy was performed by abdominal hysterotomy, the development of foetal thyroid function was studied following ${ }^{131}$ I administration to the mother. These studies also enabled estimations to be made of the radiation dose to the foetal thyroid and gonads of ${ }^{131} \mathrm{I}$ or ${ }^{132}$ I to the mother. (Aboul-Khair, Buchanan, Crooks and Turnbull, 1965).

The foetal thyroid began to trap iodine about the 13th week of gestation and this function increased with age up to the 23rd week. However, the gland did not trap iodine effectively during this period and the estimated biological half life of ${ }^{131} I$ in the foetal thyroid between 13 and 19 weeks gestation was approximately 16 to 28 hours compared with 1500 hours for the normal thyroid gland.

Because of this, together with the rapid renal clearance of iodine by the mother, $5 \mu \mathrm{c},{ }^{131} \mathrm{I}$ and ${ }^{132}$ I causes less irradiation to the foetal gonads than that due to natural radiation for one year. Irradiation to the foetal thyroid exceeds that for natural sources only after 17 weeks gestation in the case of ${ }^{132} \mathrm{I}$.

\section{METABOLIC CHANGES IN THE PUERPERIUM}

\section{K. J. Dennis}

It is now generally accepted that, both for purposes of clinical investigation of patients, and for physiological studies of normal and abnormal pregnancy states, the criteria of normality applied to the non-pregnant female are not necessarily valid. The erythrocyte sedimentation rate can be taken as an example of this. In late pregnancy, the rate can be as high as $100 \mathrm{~mm}$. in the first hour (Furuhjelm, 1956). This is probably associated with changes in the concentration and molecular shape of various plasma proteins. Failure to make allowances for changes in body composition and function can lead to errors in the interpretation of clinical signs such as oedema. Such failure is even more likely to lead to the wrong significance being attached to the results of biochemical estimations.

Our understanding of the control of the many pregnancy changes is very limited. Most workers assume that changes in the endocrine environment are responsible. Although such hormonal changes have also been extensively studied the relation between endocrine function and, for example, increases in plasma volume are not yet understood; though the report by Hervey and Hervey (1964) suggesting an asso- ciation between fat storage and progesterone levels is of great interest.

At the delivery of the baby and of the placenta, the now no longer pregnant woman is in a unique situation. All the adaptations to pregnancy have fulfilled their functions and are suddenly redundant. Moreover, a potent endocrine unit, the placenta, whose hormones appear to be to a large extent modified by organs within the baby (Diczfalusy, Cassmer, Alonso and De Miguel, 1961) has ceased production. A study of the return to the nonpregnant physiological state of certain body functions during the puerperium was undertaken to ascertain how accurately the pregnancy unwinding process mirrors in magnitude the more gradual build-up in pregnancy. The first parameter studied was body weight. (Dennis and Bytheway, 1965). Figures 1 and 2 (taken from their paper) show that, on average, in primiparae who had not shown any oedema in late pregnancy, and in almost all parous patients, there is a period of 3 days during which body weight rises by up to as much as 3-4 pounds in individual cases. As a rule on the 4th day weight begins to fall. This fall is quite rapid over the next 3 days, and then 


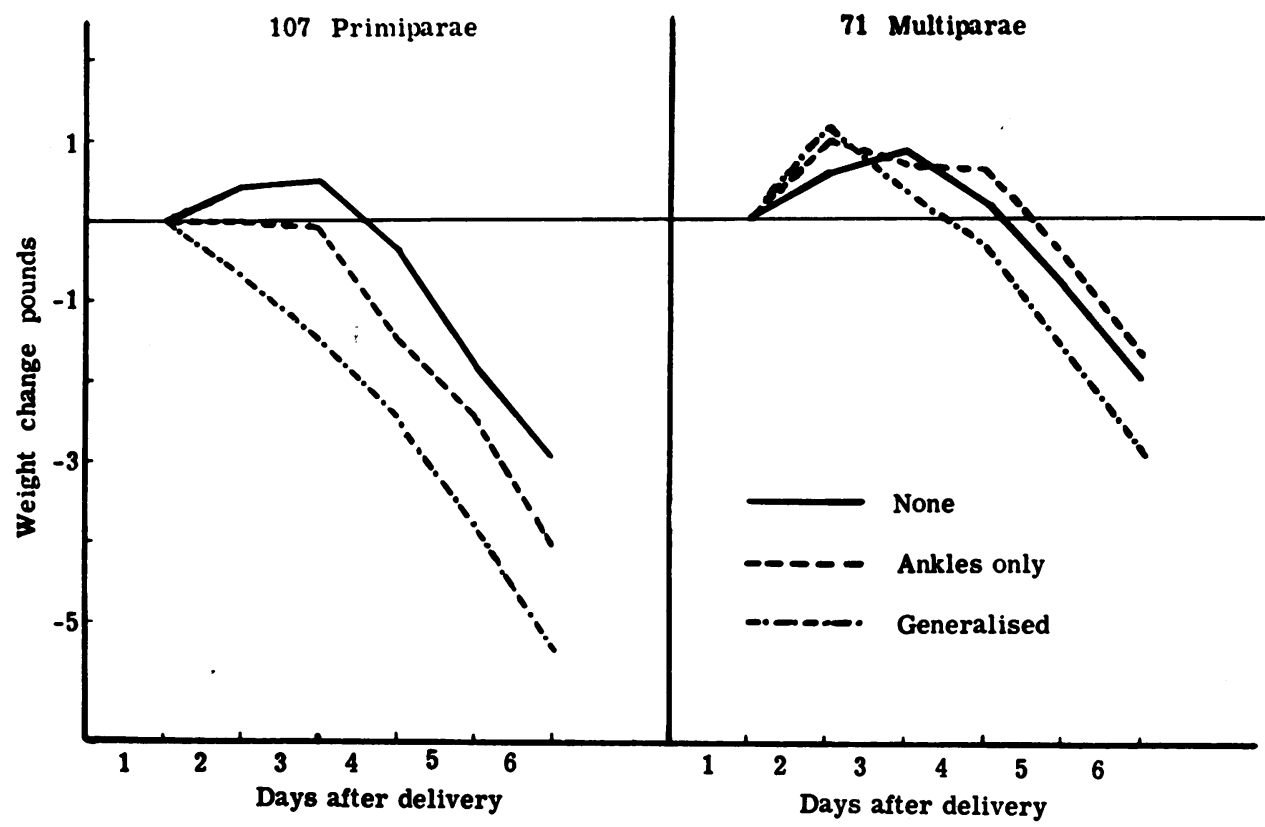

FIG. 1- Body weight changes in the puerperium by oedema groups-178 normal subjects not given Stilboestrol.

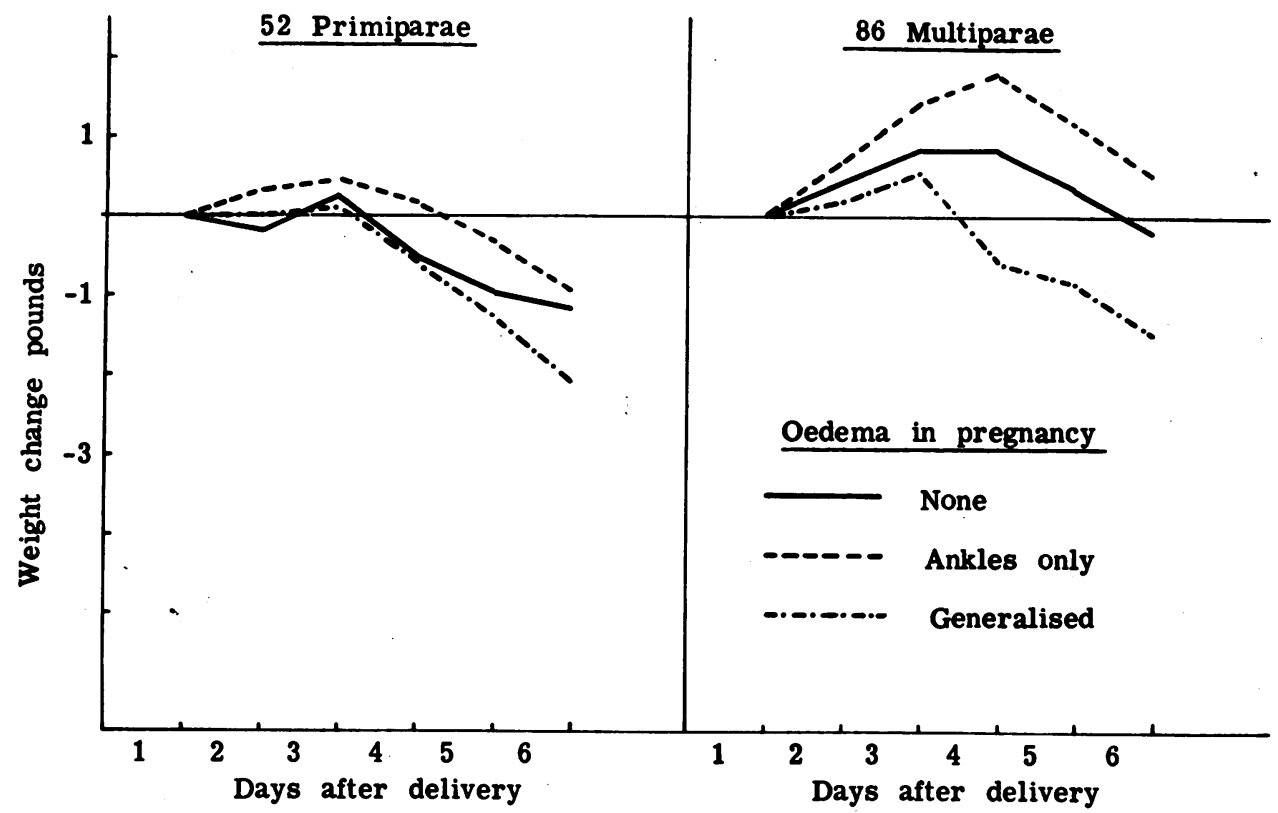

Fig. 2.-Body weight changes in the puerperium by oedema groups-138 normal subjects given Stilboestrol. 

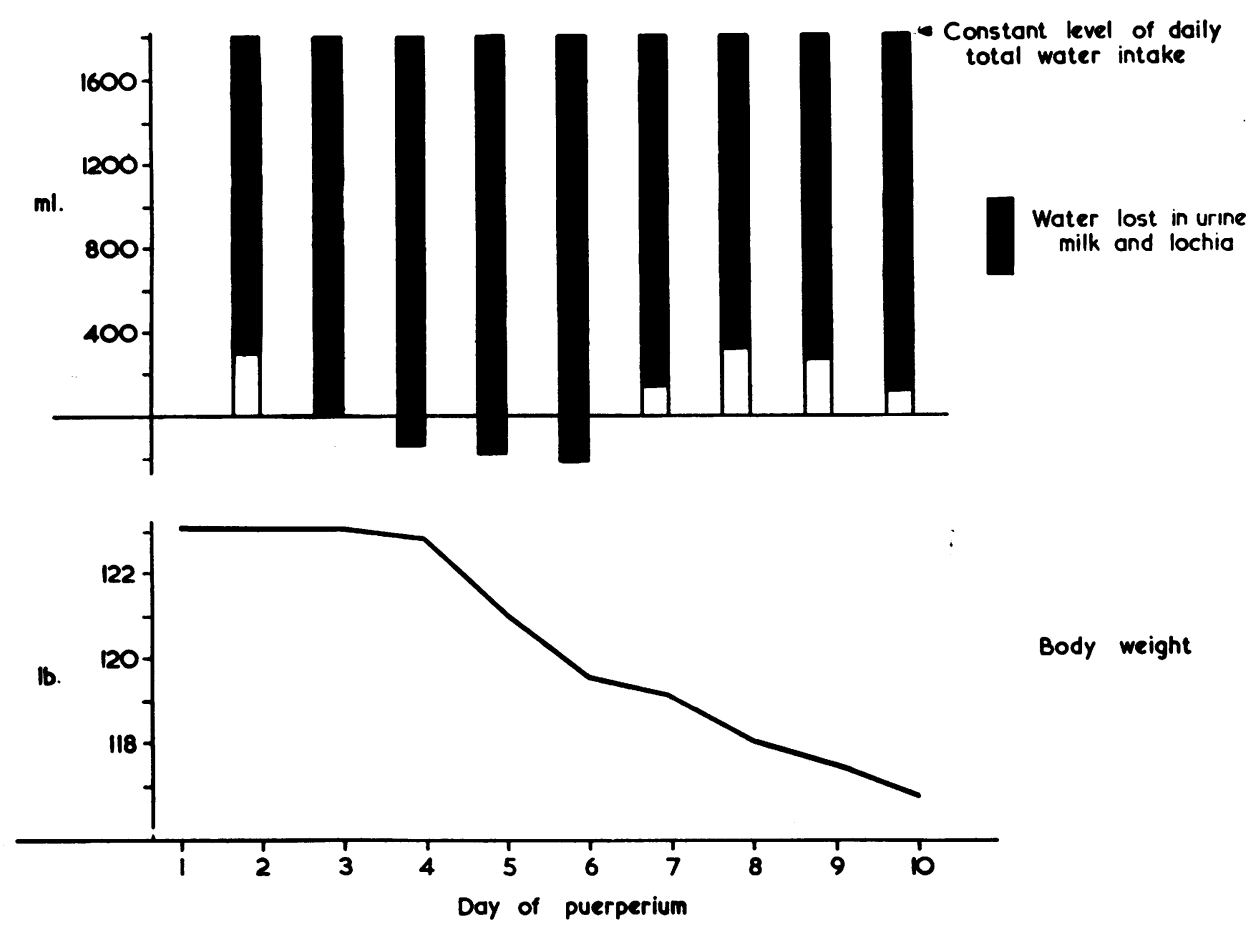

Body weight

FIG. 3- Weight change and partial water balance during the puerperium in a normal primipara.

becomes much more gradual. In approximately 40 per cent of the primiparae oedema had been noted in late pregnancy. In these, on average, the initial weight gain did not occur; indeed, especially in those women, where oedema in late pregnancy had not been confined to feet and legs, weight loss set in as soon as they were delivered. This was also the pattern in a separate group of pre-eclamptic women.

As rapid weight gains and losses from day-today are usually accounted for by changes in ing down or mobilisation of stores, an body water content rather than by sudden layexperiment labelled a "partial water balance" was devised to obtain confirmation that water is held in the body for the first 3 days postpartum. Fig. 3 shows the results of one such experiment which tends to confirm this hypothesis. We are also able to show that the administration of the synthetic "oestrogen" stilboestrol for the inhibition of lactation tends to increase the amount of gain in body weight immediately after delivery, and to reduce the rate of weight loss thereafter. This constitutes a situation in which an oestrogen has been shown to cause water retention in the human, a fact commonly assumed, largely on the basis of animal experiment. Experiments are now in progress to investigate the endocrine background of metabolic changes in the puerperium.

Body weight tends to stabilise about 10 weeks after delivery. At this time there is still a positive balance of about $2.25 \mathrm{Kg}$. compared with the calculated pre-pregnancy weight. This balance is, on average, $0.7 \mathrm{Kg}$. less in women who have continued to breast feed their babies than in those who have not lactated, or have lactated for a short period only.

The water retention occurring in the early puerperium, however brought about, is also assooiated with certain changes in the concentration of blood constituents. For example, daily estimations of the haemoglobin concentration of peripheral venous blood in the puerperium show a rise from the late pregnancy level on the first day, followed by a sharp fall to a minimum level on the 4th and 5th days. This is followed by a rapid spontaneous rise. The peripheral venous 
haematocrit behaves in a similar manner. As the mean corpuscular haemoglobin concentration remains constant throughout these changes, they were thought to be due principally to alterations in plasma volume. In women who show oedema in late pregnancy the mean level of haemoglobin concentration throughout these changes is significantly lower than in the nonoedematous cases.

Actual measurements of plasma volume and total body red cell mass confirm that, in nonoedematous primiparae, whereas the total circulating red cell volume falls slightly in the first three days after delivery, the plasma volume rises slightly at the same time. In the subsequent week the red cell mass remains static, whereas plasma volume diminishes progressively.

It would seem, therefore, contrary to common belief, that water is held in the body for 3 or 4 days after delivery, before being disposed of; and that the post-partum diuresis is thus delayed. There are several possible underlying mechanisms for this water retention. The effects on body electrolytes described by Landau and Lugibihl (1964) and on connective tissue shown by Zachariae (1959) suggest that the sex steroids are involved in control of total body water and electrolyte content, and their possible role in the puerperium is being investigated. Another possibility is that the changes are mediated by aldosterone, or hydrocortisone, either because of stress stimulation the result of labour, or because the hyperfunction of pregnancy cannot be immediately reversed.

\section{REFERENCES}

Aboul-Khair, S. A., Buchanan, T. J., Crooks, J., and TuRNBULL, A.C. (1965): The Development of Function in the Human Foetal Thyroid Gland, Abstracts of Vth Int. Thyroid Conference, Rome, p. 16.

Aboul-Khair, S. A., Crooks, J., Turnbull, A. C., and HYTTEN, F. E. (1964): The Physiological Changes in Thyroid Function during Pregnancy, Clin. Sci., 27, 195.

Aboul-Khair, S. A., Crooks, J.. Turnbull, A. C.. and Turnbul, E. (1966): Changes in Thyroid Function during Pregnancy Complicated by Preeclampsia. (In preparation).

Aboul-Khair, S. A., Crooks, J., Turnbull, A. C., and TURNBULL, E. (1966): Thyroid Function in Cases of Abortion and Premature Delivery. (In preparation).

ANDERSON, A. B. M., Turnbull, A. C., and Murray, A. (1966): The Relationship between Amniotic Fluid Pressure and Uterine Wall Tension in Pregnancy, Amer. J. Obstet. Gynec. In press.

BarTtER, F. C., LIDDLE, G. W., DUNCAN, L. E., BARBER, J. K., and DElea, C. (1956): Regulation of Aldosterone Secretion in Man: Role of Fluid Volume, J. clin. Invest., 35, 1306.
Bengtsson, L. Ph., and Csapo, A. (1962): Oxyitocin Response, Withdrawal, and Reinforcement of Defense Mechanism of the Human Uterus at Midpregnancy, Amer. J. Obstet. Gynec., 83, 1083.

Brown, J. J., DAvies, D. L., LeVER, A. F., and Robertson, J. I. S. (1965): Plasma Renin Concentration in Human Hypertension. 2: Renin in Relation to Aetiology, Brit. med. J., ii, 1215.

BURT, R. L. (1954): Peripheral Utilization of Glucose in Pregnancy and the Puerperium, Obst. and Gynec., 4, 58.

Christie, J., 'ANDerson, A. B. M., TuRnbull, A. C., and BECK, J. S. (1966): The Human Placenta and Membranes: A Histological and Immunofluorescent Study of the Effects of Intra-amniotic Injection of Hypertonic Saline, J. Obstet. Gynaec. Brit. Cwlth. In press.

Crooks, J., Aboul-Khair, S. A., Turnbull, A. C., and HYTTEN, F. E. (1964): The Inoidence of Goitre during Pregnancy, Lancet, ii, 334.

Davey, D. A., O'Sullivan, W. J., and Browne, J. C. MóC. (1961): Total Exchangeable Sodium in Normal Pregnancy and in Pre-eclampsia, Lancet, $\mathbf{i}$, 5.19.

De Alvarez, R. R., Afonso, J. F., and Sherrard, D. J. (1961): Serum Protein Fractionation in Normal Pregnancy, Amer. J. Obstet. Gynec., 82, 1096.

De Bruine, T. L. A. (1960): Aldosterone Excretion in Eclamptogenic Toxicosis, Ned. T. Verlosk., 60, 381.

DenNis, K. J., and Bytheway, W. R. (1965): Changes in Body Weight after Delivery, J. Obstet. Gynaec. Brit. Cwlth., 72, 94.

DiczFalusy, E., CASsmer, O., Alonso, C., and DE MIGUEL, M. (1961): Estrogen IMetabolism in the Human Fetus and Newborn, Recent Progr. Hormone. Res., 17, 147.

DieckmanN, W. J. (1950): In "Toxaemias of Pregnancy", Ciba Foundation Symposium, London: J. \& A. Churchill.

DunCAN, L. J. P. (1956): The Intravenous Gilucose Tolerance Test, Quart. J. Exp. Physiol., 41, 85.

Edelman, I. S., HALEY, H. B., SCHLOERB, P. R., SheldoN, D. B., FriIS-HANSEN, B. J., Stoll, G., and MOORE, F. D. (1952): Further Observations on Total Body Water; Normal Values Throughout Life Span, Surg. Gynec. Obstet., 95, 1.

Edelman, I. S., Leibman, J., O'Meara, M. P., and BIRKENFIELD, L. W. (1958): Interrelations between Serum Sodium Concentration, Serum Osmolarity and Total Exchangeable Sodium, Total Exchangeable Potassium and Total Body Water, J. clin. Invest., 37, 1236.

FURUHJELM, U. (1956): Maternal and Cord Blood; Comparative Investigation with Reference to Blood Sugar, Serum Proteins, Erythrocyte Sedimentation Rate and Total Serum Lipids, Ann. Paediat. Fenn., 2, Suppl., 5, 1 .

GALleTtI, F., and KLOPPER, A. (1964): The Effect of Progesterone on the Quantity and Distribution of Body Fat in the Female Rat, Acta endocr., (Kbh.), 46, 379.

Gilder, H., Redo, S. F., Barr, D., and Child, C. G. (1954): Water Distribution in Nonmal Subjects and in Patients with Laennec's Cirrhosis, J. clin. Invest., 33, 555.

HAGEN, A. (1961): Blood Sugar Findings during Pregnanioy in Normals and Possible Prediabetics, Diabetes, 10, 438. 
Haley, H. B., and Woodbury, J. W. (1956): Body Composition and Body Water Metabolism in Normal Pregnancy, Surg. Gynec. Obstet., 103, 227.

HARDING, V. J., and VAN WYCK, H. B. (1931): Effects of Hypertonic Saline in Toxaemias of Later Pregnancy, J. Canad. med. Ass., 24, 635.

Hervey, G. R., and Hervey, E. (1964): Effects of Progesterone on Food Intake and Body Composition in Rats, J. Endocr., 30, vii.

Hummel, F. C., Hunscher, H. A., Bates, M. F. BonNer, P., and MaceY, I. G. (1937): Consideration of Nutritive State in Metabolism of Women during Rregnancy, J. Nutr., 13, 263.

Hutchinsón, D. L., Plentl, A. A., and Taylor, H. C. JR. (1954): The Total Body Water and the Water Turnover in Pregnancy Studied with Deuterium Oxide as Isotopic Tracer, J. clin. Invest., 33, 235.

HyTteN, F., and KLOPPER, A. (1963): Response to a Water Load in Pregnancy, J. Obstet. Gynaec. Brit. Cwlth., 70, 811.

HytTEN, F. E., and LeITCH, I. (1964): "The Physiology of Human Pregnancy", Oxford: Blackwell.

Hytten, F. E., and PAintin, D. B. (1963): Increase in Plasma Volume during Normal Pregnancy, J. Obstet. Gynec. Brit. Cwlth., 70, 402.

Hytten, F. E., TAggart, N. Billiewicz, W. Z., and JASON, A. C. (1962): The Estimation of Small Concentrations of Deuterium Oxide in Water by the Falling Drop Method, Phys. in Med. Biol., 6, 415.

Ikkos, D., LJUngGRen, H., LUFT, R., and SJOGREN, B. (1955): Content and Distribution of Potassium and Chloride in Adults, Metabolism, 4, 231.

KaplaN, N. M. (1961): Tolbutamide Tolerance Test in Carbohydrate Metabolism Evaluation, Arch. intern. Med., 107, 212.

KEMSLEY, W. F. F. (1951-52): Body Weights at Different Ages and Heights, Ann. Eugen. (Lond.), 16, 3116.

KLOPPER, A. (1961): Oestriol Excretion in Preeclampsia, Path. et Microbiol. (Basel), 24, 652.

KLOPPER, A. (1964): Changes in Renal Function in Late Pregnancy, Lancet, ii, 565.

KLOPPER, A. (1966): "Research on Steroids". Ed. A. Klopper. Il Pensiero Scientifico, Rome. In press.

KLOPPER, A., and MaCnAUGHTON, M. C. (1965): Hormones in Recurrent Albortion, J. Obstet. Gynaec. Brit. Cwlth., 72, 1022.

KLOPPER, A., and STEPHENSON, R. (1966): Oestriol and Pregnanediol Excretion in Rhesus Incompatibility, J. Obstet. Gynaec. Brit. Cwlth., In press.

KLOPPER, A. I., TURNBull, A. C., and ANDERSON, A. B. M. (1966): Steroid Hormone Excretion following Intra-amniotic Injection of Hypertonic Saline, J. Obstet. Gynaec. Brit. Cwlth. In press.

LANDAU, R. C., and LugibihL, K. (1964): Advances in Treatment of Menstrual Dysfunction, p. 60. London: Henry Kimpton.

Leaf, A., BArtTer, F. C., SAntos, R. F., and Wrong, O. (1953): Evidence in Man that Urinary Electrolyte Loss Induced by Pitressin is Function of Water Retention, J. clin. Invest., 32, 868.

Louros, N. C., Miras, K., and Frangiadakis, L. (1960): Aldosterone and Pregnanediol Excretion in the Urine in Normal Pregnancy and in Pregnancy Toxaemias. (Preliminary Report), Geburtsh $u$. Fraueheilk, 20, 848.

MoCartney, C. P., Pottinger, R. E., and Harrod, J. P. (1959): Alterations in Body Composition During Pregnancy, Amer. J. Obstet. Gynec., 77, 1038 .
MaoGillivray, I. (1961a): Water and Electrolyte Metabolism. Amsterdam: Elsevier.

MacGillivray, I. (196ilb): Salt and Water Balance in Normal and Toxaemic Pregnancy, Path. et Microbiol. (Basel), 24, 639.

MacGillivray, I., and BuchanaN, T. J. (1958): Total Exchangeable Sodium and Potassium in Nonpregnant Women and in Normal and Pre-eclamptic Pregnancy, Lancet, ii, 1090.

MaCGillivray, I., Hytten, F. E., Taggart, N., and Buchanan, T. J. (1962): The Effect of a Sodium Diuretic on Total Exchangeable Sodium and Total Body Water in Pre-eclamptic Toxaemia, J. Obstet. Gynaec. Brit. Emp., 69, 458.

MaoGilliviay, I., and Tovey, J. E. (1957): A Study of the Serum Protein Changes in Pregnancy and Toxaemia, using Paper Strip Electrophoresis, J. Obstet. Gynaec. Brit. Emp., 64, 361.

McMurrey, J. D., Boling, E. A., Davis, J. M., Parker, H. V., Magnus, I. C., Ball, M., and MoORE, F. D. (1958): Body Composition: Simultaneous Determination of Several Aspects by the Dilution Principle, Metabolism, 7, 651.

Mahran, M. (1961): Sodium Metabolism in Gynaecology and Obstetrics, J. Obstet. Gynaec. Brit. Emp., 68, 597.

MEDlEY, D. R. K. (1965): The Relationship between Diabetes and Obesity: A Study of Susceptibility to Diabetes in Obese People, Quart. J. Med. N. S., 34. 1111 .

PaAby, P. (1960): Changes in Serum Prote'ns during Pregnancy, J. Obstet. Gynaec. Brit. Emp., 67, 43.

Plentl, A. A., and Gray, M. J. (1959): Total Body Water, Sodium Space, and Total Exchangeable Sodium in Normal and Toxemic Pregnant Women, Amer. J. Obstet. Gynec., 78, 472.

RoY, E. J., HARKNeSS, R. A., and KERR, M. G. (1963): Concentration of Oestrogens in Blood and Urine of Patients Suffering from Pre-eclampsia, J. Obstet. Gynaec. Brit. Emp., 70, 597.

Schloerb, P. R., Friis-Hansen, B. J., Edelman, I. S., SOlOMON, A., and MOORE, F. D. (1950): Measurement of Total Body Water in Human Subjects by Deuterium Oxide Dilution with Consideration of Dynamics of Deuterium Distribution, J. clin. Invest. 29. 1296.

STRAuSS, M. (1937): Observations on Etiology of Toxemias of Pregnancy; Production of Acute Exacerbation to Toxemia by Sodium Salts in Pregnant Women with Hypoproteinemia, Amer. J. med. Sci., 194, 772.

Turnbull, A. C. (1962): Amniotic Pressure, Cervical Dilatation and the Cervix in Labour, J. Obstet. Gynaec. Brit. Cwlth., 69, 1047.

Turnbull, A. C., and ANDERSON, A. B. M. (1965): Changes in Uterine Contractility following Intraamniotic Injection of Hypertonic Saline to Induce Therapeutic Abortion, J. Obstet. Gynaec. Brit. Cwlth., 72, 755 .

Turnbull, A. C., and ANDERson, A. B. M. (1966): Intra-amniotic Hypertonic Saline, Brit. med. J., i, 672.

Welsh, G. W. (1960): Studies of Abnormal Glucose Metabolism in Pregnancy, Diabetes, 9, 466.

ZACHARIAE, F. (1959): Acid Mucopolysaccharides in the Female Genital System and their Role in the Mechanism of Ovulation, Periodica, p. 13, Copenhagen. Bogtrgkkeriet, Jorum.

ZAK, G. A., and EARLE, D. P. (1957): Blood Volume and Body Water in Normal Hospital Subjects, J. lab. Clin. Med., 49, 504. 